\title{
Chilblains in Turkey: a case-control study*
}

\author{
Z Meltem Akkurt ${ }^{1}$ \\ Safiye Kutlu Yürüker ${ }^{2}$
}

\author{
Derya Ucmak ${ }^{1}$ \\ Heybet Özkaya Celik
}

Kenan Yildiz ${ }^{2}$

\begin{abstract}
BACKGROUND: Chilblains are rather common in winter months in our country. OBJECTIVEs: Determination of demographical and clinical characteristics of patients presenting with chilblains in Diyarbakir, Turkey. Evaluation of body mass index (BMI) as risk factor for development of chilblains. METHODS: Sixty-nine patients who were diagnosed as chilblains at our outpatient clinics were included in this study. No exclusion criteria were sought. Demographical data including height and weight and answers to questions related to personal history were recorded. A control group consisting of 108 controls were chosen from among patients presenting with complaints of hair loss. Statistical analyses were conducted using SPSS 17.0. RESULTS: Of the 69 patients with chilblains, $45(65.2 \%)$ were females and $24(34.8 \%)$ were males. Mean age $( \pm S D)$ of the patients was $21 \pm 9.71 .2 \%$ of the patients complained of itching, $51.6 \%$ of pain, $31.3 \%$ of burning in the lesions. $61.3 \%$ of the patients reported recurrence of the lesions every winter season. Mean BMI of the patients was 20.5 2.9. Mean BMI of the controls was $22.4 \pm 3.7$ and the difference was statistically significant ( $\mathrm{p}=0.01$ ). ConCLUSIONS: Low BMI may be a risk factor contributing to development of chilblains in persons exposed to cold weather conditions. Apart from external factors, there seems to be a personal tendency to develop lesions, as many patients report recurrences every year. Diagnosis of chilblains requires wariness, as history of cold exposure may not be evident.
\end{abstract}

Keywords: Body mass index; Chilblains; Cold climate

\section{INTRODUCTION}

Chilblains (also known as perniosis) is a localized disease which presents as inflammatory, erythematous or purple, intensely pruritic or painful acral lesions. It is seen in susceptible individuals after prolonged exposure to nonfreezing cold temperatures and damp conditions ${ }^{1,2}$ Appearance of the lesions is approximately 12-24 hours after exposure to cold and spontaneous resolution is usually seen in one to three weeks. ${ }^{2,3}$ Chilblains can can present as a secondary feature of diseases such as systemic lupus erythematosus, Behçet disease, chronic myelomonocytic leukemia, metastatic breast carcinoma, cryoglobulinemia, cryofibrinogenemia, cold agglutinin disease, macroglobulinemia, Aicardi-Goutieres syndrome and anorexia nervosa. ${ }^{4,5}$ Laboratory investigations and cutaneous biopsy may be performed when lesions are persistent or when there is suspicion of underlying systemic disease.
Diyarbakir is located in southeastern Turkey $\left(37.88^{\circ} \mathrm{N}, 40.10^{\circ} \mathrm{E}\right)$. The climate in this region is semiarid and mean temperatures in winter months are recorded around $1-5^{\circ} \mathrm{C} .{ }^{6}$ The winter of $2011-2012$ wasparticularly colder than previous years and there was a clear increase in the number of chilblains patients. Thus, we aimed to determine the demographic characteristics of patients with chilblains and investigate whether low BMI may be a factor predisposing coldexposed individuals to chilblains.

\section{METHODS}

Approval of the local Ethics Committee of Dicle University Faculty of Medicine was obtained. Patients presenting to the dermatology outpatient clinics of Diyarbakir Training and Research Hospital between November 2011 and April 2012 who were diagnosed as chilblains were included in this study. Sixtynine patients' demographical data including height 
and weight were recorded. Information on location of cold exposure, presence of the same lesions in the previous winter and presence of the same lesions in a first degree relative was obtained. A group of 108 controls were selected from patients presenting with complaints of increased hair loss, but without alopecia on examination. Controls were chosen from patients attending our outpatient clinics to ensure a similar socioeconomic background. We anticipated patients complaining of hair loss to be of similar age and gender compared to patients with chilblains. Analysis of data was done using chi-square, students' t-test and binary logistic regression, on SPSS 17.0. P<0.05 was considered significant.

\section{RESULTS}

Gender: Of the 69 patients with chilblains, 45 $(65.2 \%)$ were females and $24(34.8 \%)$ were males. A control group of 108 patients presenting with complaints of hair loss were included (61 females and 47 males).

Age: The age range of the patients was 10 to 66 . Mean age $( \pm S D)$ of the patients with chilblains was $21 \pm 9$. Mean age of the female patients was $21 \pm 9$ and the mean age of the male patients was $22 \pm 10$. Two patients $(2.9 \%)$ were 10 years old. Seven patients $(10.1 \%)$ were between $11-15$ and 32 patients (46.3\%) were between 16-20. Twenty-one patients $(30.4 \%)$ were in the third decade. Five patients (\%7.2) were in the fourth decade and only two patients were aged 50 and over.

Symptoms: $71.2 \%$ of the patients complained of itching, $51.6 \%$ of pain, $31.3 \%$ of burning, $6.2 \%$ of numbness, $6.1 \%$ of stinging in the lesions. Patients without any complaints comprised $3.1 \%$. None of the patients had any symptoms related to systemic disease.

Clinical findings: Only the feet were involved in $50.7 \%$ and only the hands were involved in $26.1 \%$. Both the hands and feet were involved in $23.2 \%$. Acral cyanosis was observed in $23.2 \%$. Capillary refill time was normal ( $<2$ seconds) in all patients. The lesions were sensitive erythematous, purplish, edematous plaques. Ulcerated lesions were not observed. Of the hand lesions, $84.8 \%$ were only on the dorsal side of the fingers whereas $15.2 \%$ were on both dorsal and volar sides of the fingers. 9.1\% also had lesions on either the metocarpophalangeal joints or the palms. The mean number of fingers with lesions of chilblains was seven. Among lesions of the feet, $51.3 \%$ were located on the dorsal sides of the toes, $41.0 \%$ were both dorsal and volar and $7.7 \%$ were only on the volar sides of the toes. In addition, $17.9 \%$ of the patients also had lesions localized to the lateral surfaces or plantar areas. The mean number of toes with lesions was five.

Personal history: Employment status was as follows: $40.6 \%$ of the patients were employed, $30.5 \%$ did not work, $28.8 \%$ were students. Patients stating that they had no idea on which location they had been exposed to the cold comprised $34.5 \%$. 31.0\% reported their work environment, $22.4 \%$ their home, $12.1 \%$ the outdoors as the location they had been exposed. 16.3\% of patients with chilblains reported that they smoked. $25.2 \%$ of the controls reported smoking. There was statistically no difference between the groups. None of the patients reported any systemic disease. $61.3 \%$ of the patients reported recurrence of the lesions every winter season. History of similar complaints in a first degree relative was reported by $19.6 \%$ of the patients (Table 1 ).

BMI: Mean BMI of patients with chilblains was 20.5 \pm 2.9 (range 14.3-26.1). Mean BMI of the controls was $22.4 \pm 3.7$ and the difference was statistically significant $(\mathrm{p}=0.01) .15$ patients $(21.7 \%)$ were underweight (BMI<18.5), 49 patients $(71.0 \%)$ were of normal weight (BMI 18.5-25.0), 5 patients $(7.2 \%)$ were overweight. Mean BMI of females with chilblains was 20.0 \pm 2.7 . Mean BMI of males with chilblains was $21.5 \pm 3.0$ and the difference was statistically significant $(p=0.033)$. Since mean BMI values of females and males were significantly different, a binary logistic regression analysis was performed to evaluate BMI independently (Table 2).Interactions between risk factors were tested and were not significant. The odds ratio of lower BMI being a risk factor for chilblains was calculated to be 1.20 (confidence interval: 1.08-1.33).

\section{DISCUSSION}

Chilblains is still frequently encountered throughout the winter season in the setting of socioeconomic conditions predisposing to prolonged cold exposure. Patients frequently are teenagers or young adults and females are more prone. Lesions usually affect the toes and dorsum of the proximal phalanges. Lesions begin in fall or winter and disappear in spring or early summer. Common features leading to diagnosis of chilblains include a history of exposure to cold, usually for recreational or occupational purposes,

TABLE 1: Symptoms and personal history of the patients

\begin{tabular}{lll}
\hline & Yes (\%) & No (\%) \\
\hline Itching & 71.2 & 28.8 \\
Pain & 51.6 & 48.4 \\
Burning & 31.3 & 68.7 \\
Acral cyanosis & 23.2 & 76.8 \\
Smoking & 16.3 & 83.7 \\
Recurrence & 61.3 & 38.7 \\
Family history & 19.6 & 80.4 \\
\hline
\end{tabular}


TABLE 2: Binary logistic regression analysis of data

\begin{tabular}{|c|c|c|c|c|c|c|c|c|c|}
\hline \multirow{6}{*}{ Step $1^{\mathrm{a}}$} & & \multirow[b]{2}{*}{ B } & \multirow[b]{2}{*}{ SE } & \multirow[b]{2}{*}{ Wald } & \multirow[b]{2}{*}{ df } & \multirow[b]{2}{*}{ Sig. } & \multirow[b]{2}{*}{$\operatorname{Exp}(B)$} & \multicolumn{2}{|c|}{ 95\% CI for $\operatorname{EXP}(B)$} \\
\hline & & & & & & & & Lower & Upper \\
\hline & Gender & ,291 & ,334 & 758 & 1 &, 384 & 1,337 & 695 & 2,573 \\
\hline & Age & ,006 & 023 & ,066 & 1 & ,798 & 1,006 & ,962 & 1,052 \\
\hline & BMI &,- 184 & ,059 & 9,639 & 1 & ,002 & 832 & 741 & ,934 \\
\hline & Constant & 3,215 & 1,150 & 7,810 & 1 & ,005 & 24,893 & & \\
\hline
\end{tabular}

* $\mathbf{B M I}=$ body mass index; $\mathbf{S E}=$ Standard error; $\mathbf{C I}$ = confidence interval

along with presence of painful or itchy erythematous skin lesions affecting distal extremities, especially the digits and aself-limiting course. ${ }^{7,8}$ Studies recruiting large cohorts of patients with chilblains are few in the literature. An overview of the literature is provided in table 3., ${ }^{1,7,7-13}$

Classification of lesions: Chilblains have been clinically classified according to the presence of underlying systemic disease and the course of the lesions by various authors. ${ }^{9,10}$ The terms idiopathic or primaryhave been used to describe chilblains when there is no clinical and/or laboratory sign related to connective tissue disease and other underlying disorder. Atypical chilblains was termed by Viguier $e a^{10}$ to classify patients showing one to three of the revised criteria of the American College of Rheumatology (ACR) for systemic lupus erythematosus and/or any clinical or laboratory manifestations of connective tissue diseases. Takci et al ${ }^{9}$ utilized the term secondary chilblains to describe conditions in which there is known underlying disease. Again, Takci et al defined acute chilblains as lesions occurring for the first time and lasting less than eight weeks. They defined chronic chilblains as lesions lasting at least eight weeks and/or having an episodic course. Thus, the percentage of their cases with chronic chilblains $(72.5 \%)$ seemed higher than the literature and this might have been related to their definition of chronic chilblains. We agree with this, since they included patients with an episodic history into this category. In our study, $61.3 \%$ of our patients had history of a previous attack. This might be a reflection of a personal tendency to develop chilblains every winter season, but does not necessarily indicate more serious disease or underlying disorder. Viguier et al defined chronic chilblains as lesions lasting longer than one month. ${ }^{10}$

Chilblain lupus erythematosus (CLE) was one of the cohorts of Viguier's study ${ }^{10}$. These were patients who had fulfilled at least four American College of Rheumatology (ACR) revised criteria for systemic lupus erythematosus (SLE) or who had histologically ascertained cutaneous discoid lupus lesions. The Mayo Clinic criteria for chilblain LE have been defined as two major criteria (skin lesions in acral locations induced by exposure to cold or a drop in temperature and evidence of LE in the skin lesions by histopathologic examination or indirect immunofluorescence study) and four minor criteria (coexistence of SLE or other skin lesion of discoid LE, reponse to antiLE therapy, negative results of cryoglobulin and cold agglutinin studies). Both major criteria and one minor criterion need to be present to diagnose CLE. ${ }^{14}$ Nevertheless, CLE may clinically and histologically appear similar to idiopathic chilblains. ${ }^{15}$ It is possible that CLE begins as a classic acral, cold-induced lesion that then koebnerizes DLE lesions, thus explaining the spectrum of clinicohistologic findings, which seem to vary based on when, in the course of the lesion, the biopsy sample is taken. ${ }^{16}$

Incidence: Chilblains usually develop in the winter season but the exact incidence is unknown. Yang $\mathrm{et}^{\mathrm{l}} \mathrm{l}^{11}$ included 23 patients in a four-year period. Chan $e \mathrm{al}^{8}$ reported a cluster of 11 patients diagnosed in a winter season which had been harsher than usual. Gardinal-Galera et al $^{12}$ reported 10 pediatric cases in a period of five years. According to these and other similar studies, chilblains is seemingly a relatively rare diagnosis. However, the study of Raza et $a l^{1}$ from Pakistan comprised 100 patients who had been recruited in one winter season. Our study was conducted in one winter season as well. Takci et al, also from Turkey, recruited 51 patients in a two-year period. ${ }^{9}$ Chilblains has been stated to be common in southern Brazil. ${ }^{2}$ It seems that the incidence of chilblains varies depending on geographic and socioeconomic conditions and even clothing habits which differ between different regions of the world.

Age distribution: Chilblains is seen in a younger age group, usually in the second and third decade. The mean age of our cohort of patients was calculated to be 21 , which is slightly lower than similar studies.

The reason for this age distribution is not exactly known but extrinsic factors such as inadequate clothing or reckless behaviour may be involved. Nevertheless, chilblains may be seen in all ages and in fact may indicate more serious disease with advanced age. Guadagni et al identified underlying disease in 
TABLE 3: Literature overview of chilblains

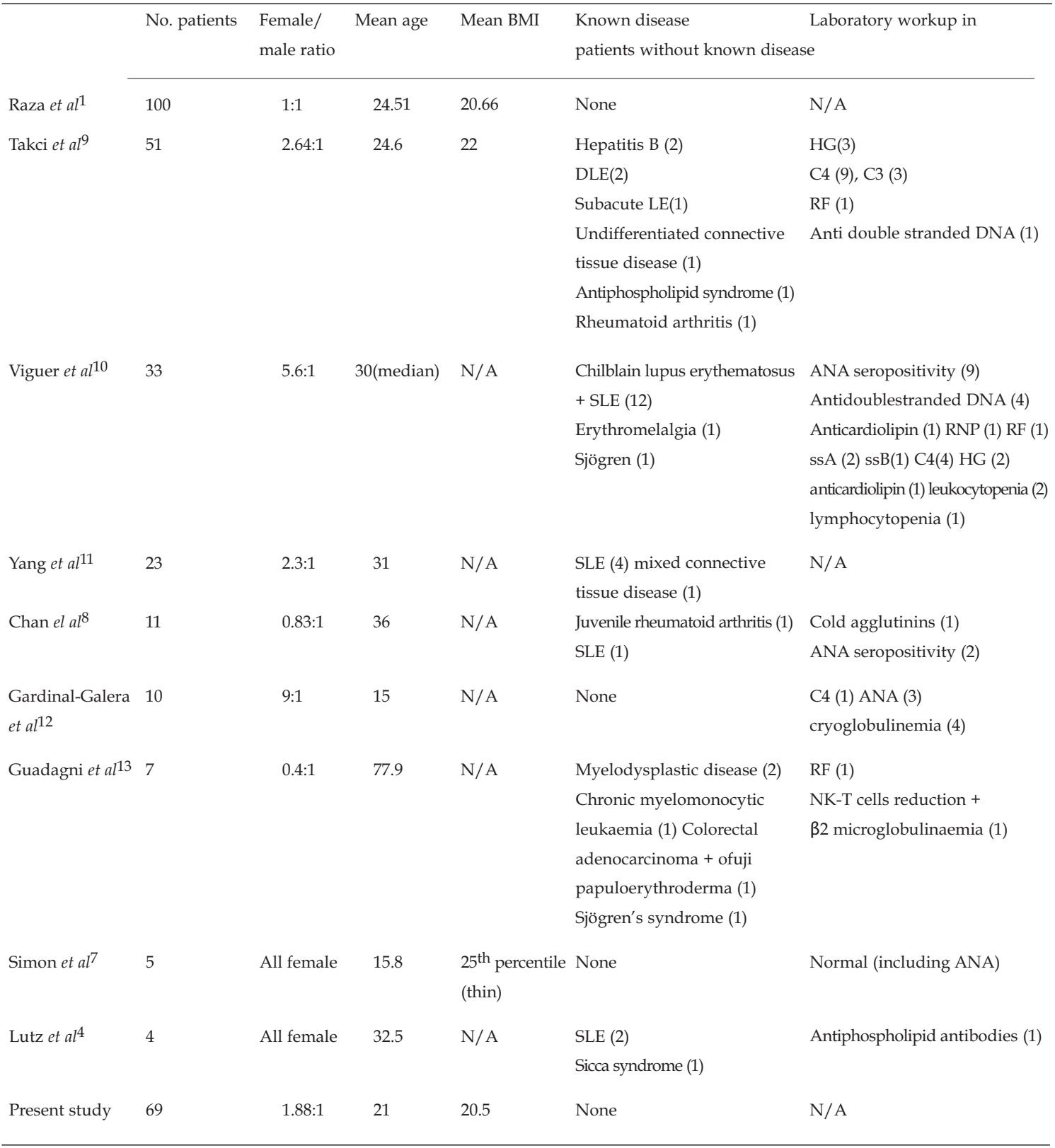

* BMI = body mass index; LE = lupus erythematosus; $\mathbf{S L E}=$ systemic lupus erythematosus; $\mathbf{A N A}=$ antinuclear antibody;

NK-T = natural killer T; RNP = anti-ribonucleoprotein antibody; RF = rheumatoid factor; HG = hypergammaglobulinemia.

five of their seven patients and emphasized that the sudden onset of chilblains in the elderly, especially male patients, might be linked to systemic disease. ${ }^{13}$ Consistent with this, Takci et al reported that the mean age of the group with secondary chilblains was signif- icantly higher than the group with primary chilblains. ${ }^{9}$ The occurrence of chilblains in children has been stated to be uncommon by Gardinal-Galera et $a l^{12}$ but Takci et al ${ }^{9}$ reported that $49 \%$ of patients in their study were aged between $0-18$. Pediatric patients 
were present in our study as well. The adolescent age group was more prone but younger children were present as well.

Gender distribution: Female-to-male ratios in the literature reflect the preponderance of females among patients with chilblains, as in our study. This may be due to intergender differences in the response of cutaneous microvasculature to cold exposure.

Body mass index: Chilblains have been reported in anorexic patients. ${ }^{5}$ Body mass indices of patients with chilblains has been repeatedly cited to be low but studies actually investigating and demonstrating this are few. Raza et $a l^{1}$ compared BMI of their patients (20.66) with controls but the difference was not significant. Mean BMI of our patients (20.5) was quite similar to theirs but the difference was significant. Our age and gender-matched control group was chosen from patients attending the same outpatient clinics of the same hospital and they were of a similar socioeconomic background and thus were assumed to be exposed to similar conditions. The mean BMI of our female patients (20.0) was significantly lower than the males (21.5). Lower BMI may indicate less adipose tissue, and thus less protection against the cold.

Occupation: Chilblains is common in people who have work or leisure pursuits such as horse-riding conducted mainly outdoors and who therefore have relatively higher exposure to cold. ${ }^{39,17}$ Takci et al ${ }^{9}$ identified clerking as the significantly most common occupation among their patients. Although clerking is not an outdoors job, the heating of the workplace might be insufficient. We encountered patients with various occupations such as cashiers, tailors, salesmen who reported underheating of their work environment. Takci et al ${ }^{9}$ in addition suggested that one of the reasons for the young age distribution of chilblains might be due to the fact that young people who leave school often work in places of employment with poor heating systems. An interesting case was the reported development of chilblains in a Moh's histotechician who worked indoors, but with a cryostat. ${ }^{18}$ Thus, we can conclude that the relation of occupation to chilblains is in the context of exposure in some way to the cold.

History of cold exposure: Chan et al $l^{8}$ noted that Hong Kong experienced its longest cold spell in the past 40 years and seven of their 11 patients gave an antecedent history of prolonged exposure to cold. Takci et al $l^{9}$ reported that $61 \%$ of their patients did not have central heating in their home. Electrical heaters are the main heat source during the winter in many homes in Diyarbakir where costs of heating are a concern for many people, leading to inadequacy of indoor heating. Some of our patients reported underheating either in their home or workplace, and this made it difficult to ascertain whether cold injury occured out- doors or indoors. In addition, history of exposure to cold is not always evident in patients with chilblains, as $34.5 \%$ of our patients had no idea on the setting they had been exposed. Obliviousness may be a reason, as it is also a cause for the lesion itself. Risk of chilblains can be decreased by education, knowledge, and appropriate behavior. ${ }^{1}$

Other factors related to chilblains: Raza et al ${ }^{1}$ reported that history of chilblains in first-degree relatives, complaints of numbness and tingling sensations of the fingers or toes, frequent hand and foot washing and lower consumption of tea during winter months were reported to be significant risk factors for development of chilblains. History of chilblains in firstdegree relatives was observed in $19.6 \%$ of our patients. Clothing habits have been suggested in be involved in development of chilblains and proper clothing and protection from the cold is advised in treatment. Wearing tight low-cut jeans for a prolonged time has been reported as a risk factor for chilblains on the hips. ${ }^{19}$ Two patients in the series by Simon $e t a l^{7}$ reported wearing sandals in winter.

Underlying systemic disease: Studies questioning the necessity of a search for underlying disease in chilblains are few in the literature. Literature review revealed that the most frequently detected serological abnormalities in patients with chilblains comprise rheumatoid factor, antinuclear antibodies, gammaglobulins, antiphospholipid antibodies, complement and cryoproteins. The most frequently encountered underlying disease seems to be SLE and other connective tissue diseases. The question remains as to the significance of serological abnormality in a patient with chilblains lacking other symptoms and signs of systemic disease.

Takci et $a l^{9}$ found that persistence beyond the cold season, photosensitivity, hypergammaglobulinemia and presence of rheumatoid factor were significant findings in secondary chilblains and all patients in this group $(14 \%$ of all patients) had a chronic course.

One patient with chronic chilblains developed subacute LE during the follow-up. The authors stated that the significance of the clinical and immunological abnormalities in the group with chronic lesions remains unclear and recommended a long-term clinical follow-up for chronic chilblains because of the possibility of associated disorders. Viguier $e t a l^{10}$ included patients affected for more than one month in their study and found that chilblains with a chronic course may reveal connective tissue disease. Twelve of their patients had known SLE. They also found that female gender and persistence of lesions beyond the cold seasons were significantly more associated with chilblains and LE. The number of patients with LE reported by Takci et al was two. SLE is frequently 
associated with chilblains, and the frequency of CLE is thought to be underestimated. ${ }^{16}$ Every patient with SLE should be questioned for presence of chilblains. The relevance of a search for cryoproteins in patients with chilblains has been challenged. Yang et $a l^{11}$ reported that cryoglobulinemia was not detected in any of their 23 patients $(21 \%$ were secondary chilblains). This was also the case for Takci et al. ${ }^{9} \mathrm{We}$ did not search for autoantibodies or cold agglutinins in our patients, as none had any symptoms or signs related to underlying disease or known systemic disease. We believe that in the setting of a cold winter period and socioeconomic factors predisposing to cold exposure, the association of chilblains with underlying disease is weaker and chilblains in young patients usually is a self-limiting disease not requiring elaborate investigation.

Nevertheless, full consideration should be given to patients with persistent lesions and/or presence of symptoms and signs related to systemic disease, especially connective tissue diseases, and detailed investigation should be undertaken if there are any. Extra attention should be paid to patients at the ends of the age spectrum, especially the elderly. ${ }^{13}$

The phenomenon of cold-induced vasodilatation: Exposure to cold or dressing inadequately are no doubt important, but it is obvious that some subjects are essentially more prone, as observed by the high percentage of our patients reporting recurrences every winter season. The development of chilblains in a cold-exposed individual may be hypothesized to be linked to interpersonal variations in the phenomenon of cold-induced vasodilatation (CIVD), which is defined as a cyclic increase in extremity cutaneous blood flow which in turn causes an increase in local tissue temperature. CIVD is observed about 5-10 minutes after onset of cold exposure and has been suggested to provide cryoprotective function. CIVD is important in maintaining tissue integrity, minimizing the risk of cold injuries, and likely improving manual dexterity and performance and alleviating pain. ${ }^{20,21}$

The relative frequency of chilblains in females may be due to differences in the CIVD response. Although it is stated that females have lower hand blood flows when exposed to the cold due to increased vascular reactivity, in a study conducted by
Midttun, no significant difference in blood flow rate in thumbs or toes was observed between men and women. ${ }^{20,22}$ Gender differences in cutaneous microvasculature remain to be elucidated. Other factors influencing the CIVD response may be investigated in patients with recurrent chilblains. Repeated exposure to cold may result in an enhanced circulation to the extremities and training of the CIVD response may be attempted in patients predisposed to chilblains. ${ }^{23}$

The CIVD response is thought to be mediated by arterio-venous anastomoses (AVAs) in the skin. AVAs are specific thermoregulatory organs that regulate blood flow in the cold and heat via alternating periods of vasodilation and vasoconstriction. Anastomoses are not fixed structures but they can develop when necessary and disappear when they are no longer needed. AVAs are found in the skin of the inside of the hand and foot, the nail bed, the elbow, lips, cheeks, ears and the nose. ${ }^{20,21}$ The fact that chilblains usually affects the dorsal sides of the fingers may be explained by the lack of AVAs in these areas. Involvement of the feet was more frequent in our patients and involvement of the volar sides of the fingers were less than involvement of the volar sides of the toes. The underlying reasons for this may be that blood flow rate in the pulp of fingers is significantly higher than in the pulp of toes in all adult subjects. The amount of AVAs is greater in the pulp of the fingers than in the toes.2. The variability of number of affected fingers may be due to the variation of the CIVD response between fingers of the same hand.

\section{CONCLUSION}

Low BMI may be a predisposing factor for development of chilblains in cold-exposed individuals. Apart from external factors, there seems to be a personal tendency to develop lesions, as many patients report recurrences every year. Diagnosis of chilblains requires wariness, as history of cold exposure may not be evident. Detailed investigation should be undertaken in patients presenting with chronic lesions or symptoms of underlying systemic disease. $\square$ 


\section{REFERENCES}

1. Raza N, Habib A, Razvi SK, Dar NR. Constitutional and behavioral risk factors for chilblains: A case-control study from Pakistan. Wilderness Environ Med. 2010;21:17-21.e1.

2. Tonoli RE, Souza PR. Case for diagnosis. Chilblains. An Bras Dermatol. 2012;87:649-50

3. Vano-Galvan S, Martorell A.. Chilblains. CMAJ. 2012;184:67.

4. Lutz V, Cribier B, Lipsker D. Chilblains and antiphospholipid antibodies: report of four cases and review of the literature. Br J Dermatol. 2010;163:645-6.

5. White KP, Rothe MJ, Milanese A, Grant-Kels JM. Perniosis in association with anorexia nervosa. Pediatr Dermatol. 1994:11:1-5.

6. worldclimate.com [homepage on the Internet]. Robert Hoare. Worldclimate. [cited 2012 Jun 3]. Available from: URL: http://www.worldclimate.com/cgi-bin/data.pl? ref $=$ N37E040+ $1102+17280 \mathrm{~W}$.

7. Simon TD, Soep JB, Hollister JR. Pernio in children. Pediatrics. 2005;116:e472-5.

8. Chan Y, Tang W, Lam WY, Loo S, Li S, Au A, et al. A cluster of chilblains in Hong Kong. Hong Kong Med J. 2008:14:185-91.

9. Takci Z, Vahaboglu G, Eksioglu H. Epidemiological patterns of perniosis, and its association with systemic disorder. Clin Exp Dermatol. 2012;37:844-9.

10. Viguier M, Pinquier L, Cavelier-Balloy B, de la Salmonière P, Cordoliani F, Flageul B, et al. Clinical and histopathologic features and immunologic variables in patients with severe chilblains. A study of the relationship to lupus erythematosus. Medicine (Baltimore). 2001;80:180-8

11. Yang X, Perez OA, English JC 3rd. Adult perniosis and cryoglobulinemia: a retrospective study and review of the literature. J Am Acad Dermatol. 2010;62:e21-2.

12. Gardinal-Galera I, Pajot C, Paul C, Mazereeuw-Hautier J.. Childhood chilblains is an uncommon and invalidant disease. Arch Dis Child. 2010;95:567-8.

13. Guadagni M, Nazzari G. Acute perniosis in elderly people: a predictive sign of systemicdisease? Acta Derm Venereol. 2010;90:544-5.

14. Su WP, Perniciaro C, Rogers RS 3rd, White JW Jr. Chilblain lupus erythematosus (lupus pernio): a clinical review of the Mayo Clinic experience and proposal of diagnostic criteria. Cutis. 1994:54:395-9.

15. Hedrich CM, Fiebig B, Hauck FH, Sallmann S, Hahn G, Pfeiffer C, et al. Chilblain lupus erythematosus - a review of literature. Clin Rheumatol. 2008;27:949-54..

16. Costner MI, Sontheimer RD. Lupus erythematosus. In: Wolff K, Goldsmith LA, Katz SI, Gilchrest BA, Paller AS, Leffel DJ, editors. Fitzpatrick's Dermatology in General Medicine. New York: McGrawHill; 2008. p.156.

17. Haus G, Utikal J, Goerdt S, Kurzen H. Red and purple maculas and plaques at the lateral aspects of the thighs. J Dtsch Dermatol Ges. 2008:6:149-50.

18. Ayli EE, Ingraffea A, Weinman M, Gloster HM Jr. Chilblains in a Mohs histotechnician. Dermatol Surg. 2012;38:1555-6.

19. Weismann K, Larsen FG. Pernio of the hips in young girls wearing tight-fitting jeans with a low waistband. Acta Derm Venereol. 2006;86:558-9.

20. Keramidas ME, Musizza B, Kounalakis SN, Mekjavic IB. Enhancement of the finger cold- induced vasodilation response with exercise training. Eur J Appl Physiol. 2010;109:133-40.

21. Daanen HA. Finger cold-induced vasodilation: A review. Eur J Appl Physiol. 2003:89:411-26

22. Midttun M. Blood flow rate in arteriovenous anastomoses: from the cradle to the grave. Clin Physiol. 2000;20:360-5.

23. Cheung SS, Daanen HA. Dynamic adaptation of the peripheral circulation to cold exposure Microcirculation. 2012 Jan;19(1):65-77.
MAILING ADDRESS:

Z Meltem Akkurt

Dicle Universitesi Tip Fak Dermatoloji AD

Diyarbakir, Turkey

E-mail:meltem@doctor.com

How to cite this article: Akkurt ZM, Ucmak D, Yildiz K, Kutlu Yürüker S, Özkaya Celik H. Chilblains in Turkey: a case-control study. An Bras Dermatol. 2014;89(1):44-50. 